\title{
TOWARDS AGILE PRODUCT DEVELOPMENT - AN EMPIRICAL STUDY ON AN E-BIKE DRIVE
}

\author{
Zorko, Damijan (1); \\ Černe, Borut (1); \\ Tavčar, Jože (2); \\ Demšar, Ivan (1) \\ 1: University of Ljubljana; \\ 2: Lund University
}

\begin{abstract}
Today's rapidly evolving and changing market dictates constant changes in design requirements during the development process of a product. If development teams are unable or unwilling to adapt to these changes, this will ultimately lead to an uncompetitive product. How the change in requirements will affect the development process depends on the complexity of the product and the development phase in which the change in requirements occurs. The principles of Agility and the methods that follow these principles help in the successful introduction of changes in the product development process. The paper provides guidelines for the development of complex physical products taking into account the principles of Agility. The guidelines were set based on a critical review of the e-bike drive development process.
\end{abstract}

Keywords: Design methodology, Design process, Integrated product development, E-mobility, Agile

\section{Contact:}

Zorko, Damijan

University of Ljubljana

Faculty of Mechanical Engineering

Slovenia

damijan.zorko@lecad.fs.uni-lj.si

Cite this article: Zorko, D., Černe, B., Tavčar, J., Demšar, I. (2021) 'Towards Agile Product Development - An Empirical Study on an e-Bike Drive', in Proceedings of the International Conference on Engineering Design (ICED21), Gothenburg, Sweden, 16-20 August 2021. DOI:10.1017/pds.2021.582 


\section{INTRODUCTION}

Competition in the global marketplace demands functional products of ever-increasing complexity, shorter delivery lead-time, and lower cost. The main challenge related to the product development process is how to make engineering teams more efficient, innovative, and at the same time reduce product development time. Concurrent engineering and lean methodology were successfully practiced in the last two decades (Stjepandić, Wognum, and Verhagen 2015; Duhovnik and Tavčar 2015; Tavčar, Demšar, and Duhovnik 2018), however, several challenges in the optimization of product development still remain. A relatively newer approach, i.e. the Agile product development (APD) has proven to be a very useful tool in software product development (Younas et al. 2018; Tam et al. 2020; Islam and Storer 2020) but it has so far seen only limited implementation in the development of physical products.

The term Agile development was first introduced in the Agile manifesto (Beck et al. 2001). With it, the authors outlined a flexible, customer-focused design methodology, where the customer satisfaction is obtained through an incremental development procedure, carried out by small selforganizing teams, where the product is constantly tested and the product requirements are not considered constant, but can change throughout the development process. As noted by Leite et al. (Leite and Braz 2016), the method advocates maximum flexibility, adaptability in planning, timebounded, quick iterations, and swift response to evolving demands (Potdar, Routroy, and Behera 2017; Leite, Baptista, and Ribeiro 2016). One of the basic premises of the APD approach is the scrum concept (Schwaber and Sutherland 2017), which is a framework for solving complex, adaptive development problems. The essence of the framework revolves around the scrum team (ST), composed of a development team, a so-called scrum master and the product owner. As noted by Ovesen (see Ovesen 2012), the scrum framework and, with it, the APD approach can be implemented in integrated product development environments. Riesener et al. dealt with the problem of the translation of APD methods to complex physical systems and concluded that existing software oriented frameworks are, in their basic form, inadequate for such problems (Riesener et al. 2019).

On the other hand, Sommer et al. argued that typical, linear product development processes like the well-established Stage-gate process also do not provide the iterative flexibility or take count of the external supports that are typical for modern day development projects (Sommer et al. 2015). As an alternative, they propose a hybrid method combining elements of the APD and Stage-gate approaches. Similarly, Smith proposed the concept of flexible product development, which holds many similarities with the APD approach developed for the software domain and showed that the concept can be used to generally improve the performance of the development process and enable incomparably higher adaptability to changes than traditional design methodologies (Smith 2007). As shown by Reichwein et al., a method to overcome the issues of translating APD from software to hardware development projects is by systematically implement additive manufacturing technologies in the development process (Reichwein et al. 2020). Additionally, an early adoption of CAD and numerical simulation tools in the development process enables the creation of virtual prototypes (VP), which can accelerate the process by forming a basis for quick evaluation, discussion and formation of new ideas inside the engineering team. Similarly, Vinodh et al. advocate the use of a combination of $\mathrm{CAD} / \mathrm{CAE}$ and rapid prototyping (RP) tools as a means to translate from linear to APD (Vinodh et al. 2010). These tools can provide for quick development iterations and testing and offer substantially improved flexibility, which can all translate in noticeable cost reduction. The APD methodology can, as noted by Potdar et al. (Potdar, Routroy, and Behera 2017; Potdar and Routroy 2018), also be implemented in industrial manufacturing, which is also a key component of a successful product market deployment. Still, Stare points to the fact that, even though many enterprises do use some components of the APD methodology, there exists a lack of systematic implementation of APD in most fields of product development (Stare 2014) (see also Raj et al. (Raj et al. 2013)). Chen et al. argue that, especially for small and medium enterprises (SMEs) the implementation of APD can be highly beneficial (Chen, Reilly, and Lynn 2012). Böhmer developed an approach for the agile development of mechatronic systems in minimum time and with minimal resources. The approach was evaluated in the automotive sector (Böhmer 2018). Gövert upgraded the model and provides seven solution elements to support the implementation of agile development in mechatronic product development process (Gövert 2020). 
The presented paper describes an empirical case study of an industrial project dealing with the development of a complex mechatronic system, namely the central drive system of a pedelec e-bike. The APD methodology showed to provide the necessary tools for a successful completion of the project, albeit several incompatibilities of the methodology with physical product development were identified. A generalized, modified APD method, tailored for the development of complex mechatronic systems, was developed, based on the experiences gained from the project.

\section{METHODOLOGY}

The study focuses on a critical review of the employed e-bike drive's R\&D process. The authors were members of scrum team (ST), who developed the mechanical part of the drive and had a good insight into the process itself. The e-bike market has been developing extremely fast in the past few years, so changes were inevitable during the development process. A specific feature of the e-bike market is that the introduction of innovations is tied to the annual season and this means additional pressure on the shortest development cycle possible. Given the demanding circumstances of the project, APD methods were used, which were adapted for the needs of product development. Based on a critical review, several key issues that could have repeatedly jeopardized the entire project, were identified, and a proposal for improvement was formulated.

An essential part of APD methods is a working prototype, which is should be tested at the end of each weekly or biweekly iteration/sprint. In the development of physical products, of course, this is not possible due to manufacturing constraints. The influence and applicability of VPs and various physical prototypes (partial or full, design or functional) were investigated. These have the potential to reduce the cost and time of prototyping in the development of more complex physical products.

\subsection{Project background}

An e-bike drive is a complex mechatronic system. In our project it had to be developed in the shortest possible time due to the rapidly developing market. At project start, the customer had developed requirements based on existing competing products and information received from end customers available to e-bike distributors. Changes in the e-bike market and constant interaction with the customer have led to multiple changes in requirements during the project. The development process of the drive system was conducted in a way that can be considered characteristic for APD in combination with concurrent engineering. In this context, an international team was formed, which included experts from the entire field of mechatronic R\&D.

\subsubsection{Team composition}

The project involved a consortium of partners whose tasks were the following:

- Partner P1: project management, system architecture, electric motor development, testing of physical prototypes

- Partner P2/buyer: system architecture, battery development and preparation for installation, communication with potential customers (bicycle suppliers)

- Partner P3: development of the mechanical part of the drive

- Partner P4: torque sensor development

- Partner P5: electronics and control development

Partner P1 had a direct contractual relationship with the buyer of the drive, while the remaining partners were in a contractual relationship with him. Also, the buyer of the drive was not the last link in the supply chain, i.e. the one, who launches the product on the market, but developed the battery and managed communication with bicycle suppliers and distributors and e-bike sellers.

The development of the entire drive was initially divided into the development of smaller subassemblies, which were: electric motor, battery set, mechanical power transmission, power and control electronics, torque and speed sensor. Individual sets were developed by different teams, and due to the interdependence between the sets, regular communication and coordination between thems was required (Figure 1). 


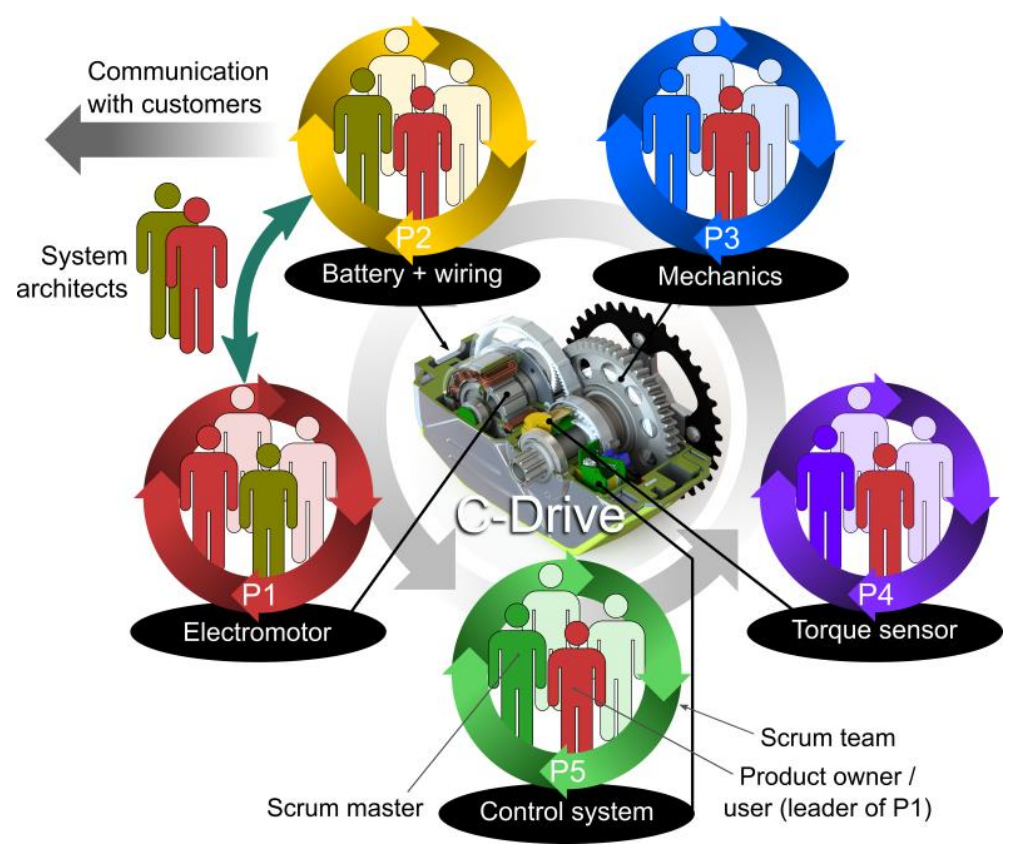

Figure 1. Product R\&D team

\subsubsection{Changes to specifications}

The initial product specifications were defined by the system architect (P2). The first change in specifications followed less than a month after the initial requirements were set and was triggered by the presentation of a VP to the buyer of the drive. The VP at this stage did not include yet power and control electronics, a torque sensor and connectors. After the presentation, the customer (bicycle supplier) got a better idea of the product and also of the capabilities of the development team, which was followed by a change in requirements. At this point, the required service life was increased by $10 \%$, while the permissible dimensions (length $12 \%$, width $7 \%$, height $4 \%$ ) and weight (by $25 \%$ ) of the drive were reduced.

Four months after the first change in requirements, a second change in specifications followed, where the required output peak power was increased by $100 \%$. Simultaneously with the required increase of power, the permissible housing temperature was reduced by $25 \%$. After some time, a second change of requirements was followed by a request for a change in the drive mounting.

Systematic changes in the requirements followed the presentations of the VPs at the end of individual sprints. After four one-week sprints, a VP was developed that met the initially set requirements. After its presentation, the customer requested a decrease in installation volume and weight of the drive, while also slightly increasing the required service life. The second change in requirements was due to developments in the e-bike market, where a competing manufacturer has just introduced a new product with higher rated power than that given in the initial requirements.

With a change in customer requirements the classic R\&D process would start again at the beginning, however, by following the APD methodology, the STs only started a new sprint when the requirements changed. In addition, the course of product development was also influenced by the STs' interdependence.

\subsubsection{The development process}

The drive system's development process is schematically presented in Figure 2. Within eight stages the STs developed a product that was suitable for placing on the market. The result of each stage was a physical prototype (only after the first stage the result was a VP, i.e. the A0). A large number of sprints were performed within each stage. The development took place in such a way that the basic components (motor, gearboxes, shafts, bearings...) were selected first and dimensioned according the available standards. This was followed by the addition of other components (clutches, sensors, housing, etc.). Throughout the process, the given restrictions were taken into account, especially in terms of space. 


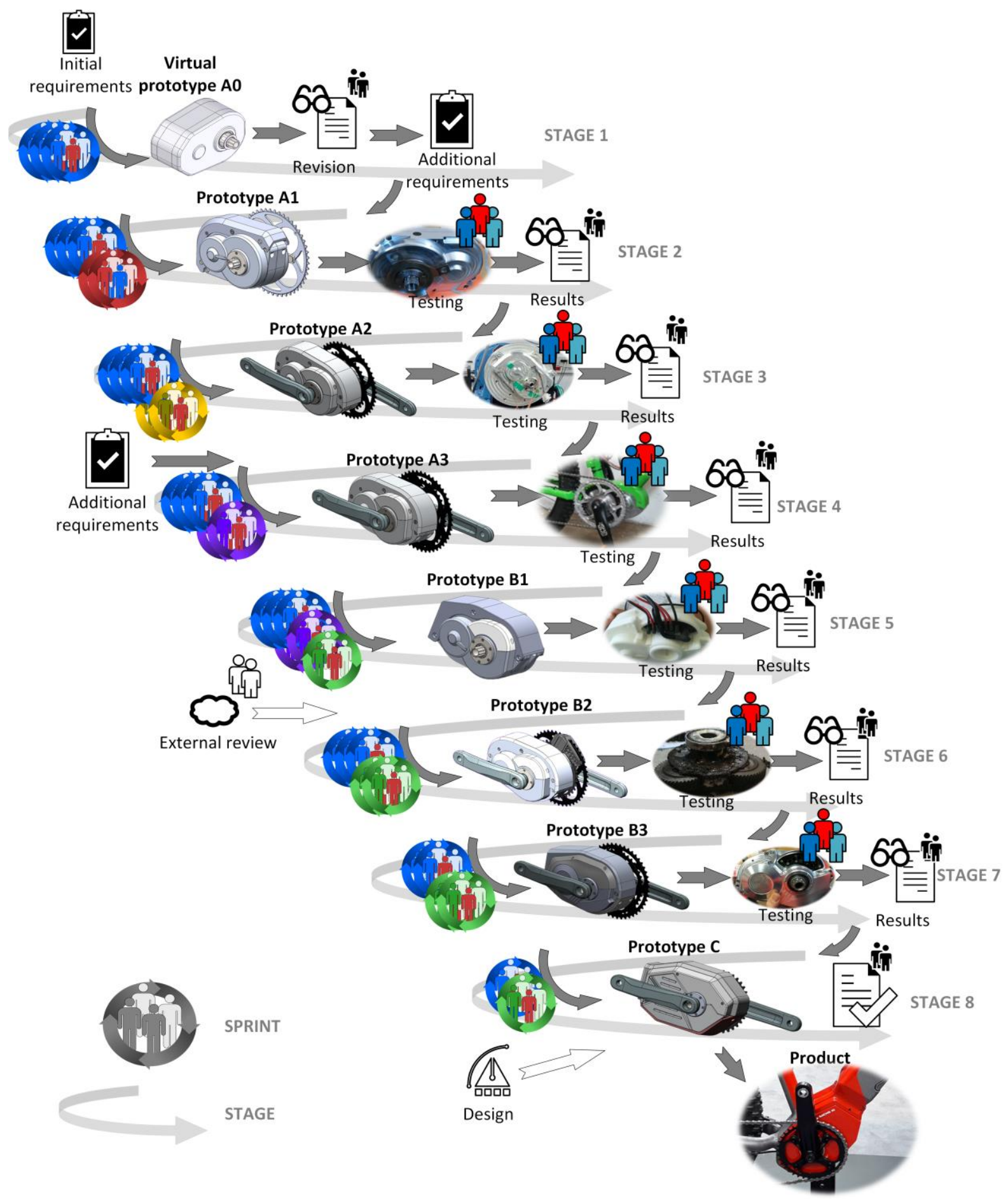

Figure 2. The drive system's development process

The presentation of the VP A0, which met all the initial requirements for the mechanical part, was followed by the first change in specifications. The ST who worked on the mechanical set, continued the new iteration considering the changed specifications. During several iterations and evaluations of the VPs, the drive design was brought to a stage that was suitable for the production of the first functional physical prototype, called the A1 prototype. At this stage, the prototype did not yet include the connectors, the torque sensor and the electronics. The A1 prototype was intended to test the functionality of the mechanical part and was tested on a test bench with a brake, otherwise intended for testing electric motors. In addition to functional testing, temperature and noise measurements were also performed on the prototype. At this stage, the complex-shaped drive housing, was fabricated on a CNC milling machine. 


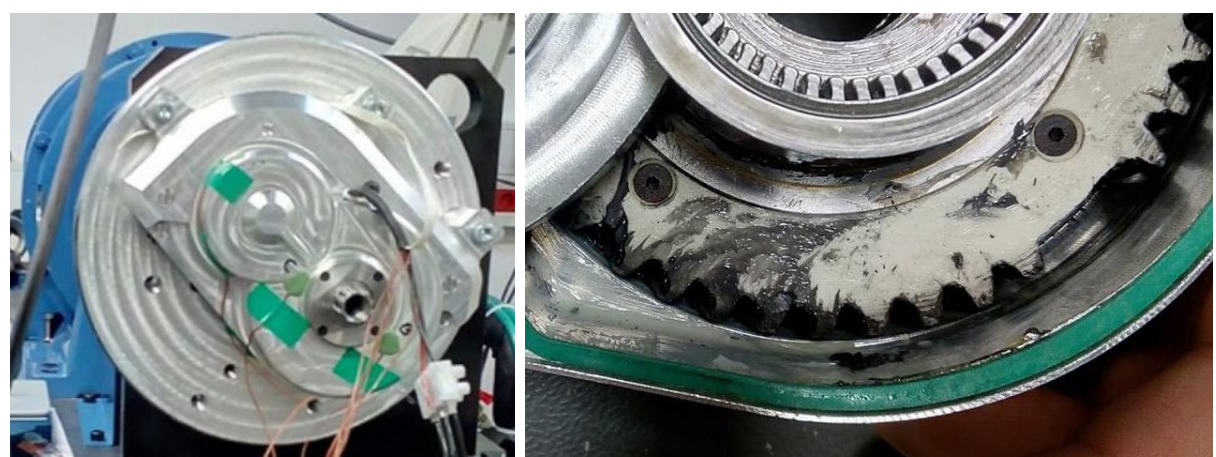

Figure 3. Testing of an A1 prototype at a test site with a brake (left) and a failure that occurred during testing (right)

After a successful deployment of prototype A1, the next step was to eliminate several shortcomings observed during the assembly and subsequent testing of the A1 prototype. At the same time, the design had to be adjusted for the installation of connectors. It was also necessary to determine the mounting points of the torque sensor and control electronics. The physical prototype A2 did not have the already mentioned assemblies installed, but the housing has already been adapted to their installation and the installation of the drive in a specially designed customised bike frame shown in Figure 4. The connector assembly was tested on a 3D printed design prototype A2 (Figure 4).
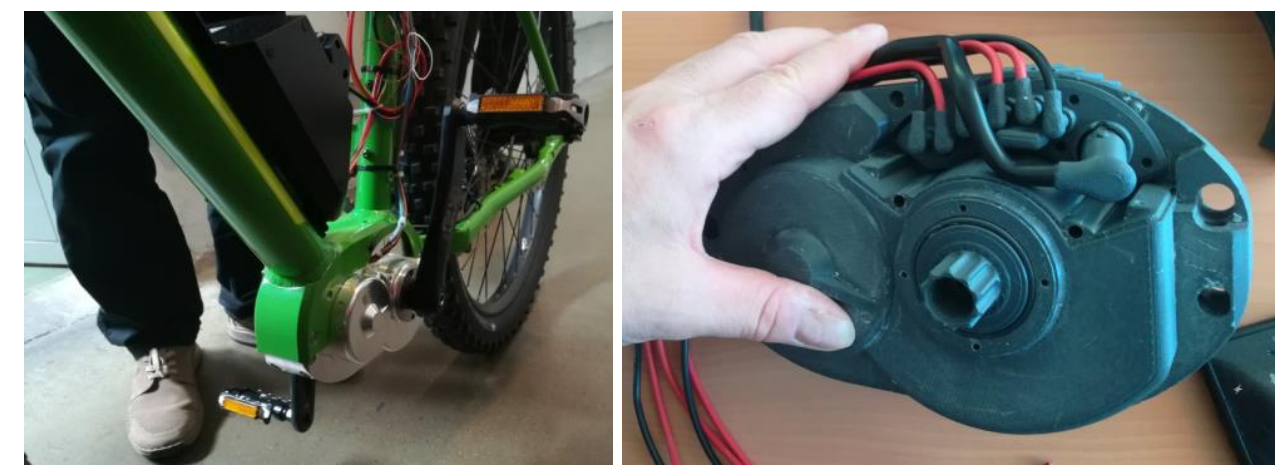

Figure 4. Functional prototype A2 tested on a bicycle (left) and a $3 D$ printed design prototype intended for testing the suitability of a set of connectors (right)

After the A2 prototype presentation, a second change in specifications occurred where $100 \%$ higher drive peak power was required, which caused considerable problems at this stage of the project. Due to the poor efficiency of the electric motor at the current gear ratio and operation at increased power, it was necessary to design a new gearbox with a higher gear ratio, which had to be installed in the same volume. The ST which developed the mechanical assembly, managed to increase the gear ratio by $25 \%$ while keeping the drive dimensions unchanged. The result was prototype A3 which had space for the installation of a connector assembly and the installation of a torque sensor and electronics (power and signal control). It was intended for testing the mechanics, and testing power and control electronics at higher required power. Temperature and noise measurements were also performed.

During the production of the A3 prototype, the customer requested a modified drive mounting to the bike's frame. The changed mounting resulted in a prototype B1 that had a modified housing, and the rest of the mechanical part remained more or less the same as the A3 prototype. When testing prototypes of versions $\mathrm{A} 3$ and $\mathrm{B} 1$, there were still several issues that needed to be resolved quickly due to the approaching agreed deadlines. Due to the involvement of members of the development team in the existing structure, an external audit was performed. Based on the findings and after coordination with the development team, corrective measures were taken that resulted in a prototype B2, which fulfilled the demanding functionalities in tests. The exterior design of the housing was added in the prototype B3, however, it was not confirmed after the presentation of the physical prototype to e-bike sellers. Thus, the customer demanded the implementation of a new industrial design, proposed by an external industrial designer, which resulted in a prototype version $\mathrm{C}$, which was approved for mass production. 


\subsection{Identification of key problems in the development process}

After project completion, a critical review of the entire development process was made and several key issues were identified. Based on this review, the following section proposes guidelines for the development of physical products, taking into account the principles of agility. Among the observed shortcomings, the following can be highlighted as crucial:

1. Physical prototypes are indispensable in brand new products, however, they require substantial resources to be produced. VPs can be very effective and a good substitute for physical ones, if the base assumptions onto which the model is built are tested and validated.

2. When VPs were introduced to buyers, changes occurred. The buyer usually finds out what he wants only when he sees a certain requirement realized, whether on a virtual or a physical prototype.

3. During development several individual partial functions that were identified as critical had to be tested. Partial physical prototypes proved essential in this regard (e.g. for independent testing of the planetary gearing or the entire gearbox without engaging the system on the crankshaft). It is important that the development team has the tools for rapid prototyping (enabling production of components of comparable quality as the final versions). It is aligned with Bernard (1999) who proposes an early embodiment, testing, and evaluation of components which "carry" the property.

4. The development of the electronic control system couldn't be carried in parallel with the mechanical system development. Until the mechanical part was fully developed and proved to be functional and robust, it was not possible to integrate and test the control system.

5. Not all engineering tools available were used in VP testing. When the input parameters change (e.g. peak power and dimensions), the requirements and limitations of individual components change significantly. To quickly adapt to such changes, it would make sense to implement software that would contain a comprehensive CAD geometry (e. g. using the so-called model-based definitionMBD-approach) and all performed calculations and analyses of individual components and subassemblies (these are updated by changing the parameters).

6. Overuse of all-hands cross-team meetings. These meetings should cover only topics relevant to all scrum teams and be held monthly or depending on the current needs but sparingly. Regular, short daily and weekly meetings should only be carried out inside an ST or directly cooperating STs.

7. Inadequate product backlog management and implementation of revisions of results after each development cycle (sprint). If the entire development team is made up of several companies, a problem arises because not everyone has access to all the information, or to the latest version of it. An additional problem was the involvement of several different partners from different locations, which made rapid communication and maintaining the proper flow of information challenging.

\section{RESULTS}

\subsection{Guideline for an agile approach to the development of complex physical products}

Based on the analysis of the e-bike drive development process and the identification of critical points, an adapted guideline for the development of complex physical products was developed, taking into account the principles of agility. The key points that the guideline envisages are described below.

1. The project R\&D team is divided into individual STs, which are interdependent and carry out the project in stages (ranging from 3 to 12 months). Each stage's result is a physical prototype. Successful stage completion by all STs results in a full physical prototype ready for testing.

2. The result of each weekly/biweekly ST sprint is an upgraded VP that must be evaluated accordingly. Numerical simulations and tools such as FMEA (Failure mode and effects analysis) can be used to evaluate VPs. What cannot be tested on VP is tested on a physical prototype, which should be adapted to the purpose of the test.

3. Ongoing product testing is key. The latter is classified into the following two categories:

A. Product acceptance testing with potential buyers

The result of each sprint is a VP. A set of functional VPs (those that, according to the analysis, meet all the set technical conditions) can be combined into a comprehensive VP, which can be presented to potential customers (this can be facilitated by the use of augmented or virtual reality hardware). By checking the customer's response, the necessary changes are identified that will contribute to the greater value of the product. Feedback received from customers should be considered as much as possible in the next iteration. Changes can be applied easier in the earlier stages of development, 
therefore communication with customers and the presentation of current results in the earlier stages (and thus the identification of customer wishes) is especially important. On physical products, changes in the later stages are much more difficult to implement than in software development.

\section{B. Technical testing of functionality}

Technical testing is done on four levels and takes place before customer testing: I. VP testing (performed during each sprint), II. testing of partial prototypes (performed in accordance with sprints that were identified as critical), III. testing of complete prototypes of each ST (performed after each stage), IV. testing of a complete physical prototype where the results of all STs are combined - a prototype of the entire product.A complete physical prototype is essential to test the functionality of the entire product. This is the result of a combination of successfully completed stages of all STs involved. Making a complete physical prototype requires substantial resources. The individual product assemblies are interconnected but are not necessarily required for testing at all stages. It is usually possible to perform tests on physical prototypes, which cover only the development work of an individual ST or a limited number of STs.

4. Segments that can be further developed while waiting for the production and testing of a physical prototype need to be identified. Strive for optimal parallelism of the development processes.

5. When developing a completely new complex physical product, the development team will encounter several critical points. Failure to cope with this can lead to failure to meet the required specifications and lag behind deadlines. External product revisions by experts who have not been involved in product development can offer a lot of fresh ideas to help us bridge the critical points.

6. Short communication chains are needed to transfer information and it is necessary to transfer it as comprehensively and as quickly as possible, without unnecessary intermediaries. The project backlogs of each project contributor should also be visible to the entire product R\&D team. Organized cloud-based solutions can provide the necessary tool to this end.

\section{Discussion}

Looking at the presented development process within the proposed guideline certain observations can be made. During the development, the STs were in constant interaction with the customer of the drive, who otherwise formed the development team one level higher, i.e. at the level of development of the entire e-bike. The entire development process was framed around the wishes of the end customer. These were recognized promptly and transmitted from the customer to the STs by the project managers and system architects of the drive.

A fixed number of members was determined in the permanent composition of the ST, the rest were included according to the phases and needs of the project. Specific knowledge and a 'greater number of hands' may be needed only at individual stages of development. There is no need for the development team to be made up of a fixed number of people, individuals can be involved in stages where their specific knowledge is required. The results of each sprint were reviewed by all members of the Scrum, as well as presented to the customer of the drive, who knew best the wishes of the end buyer, i.e. e-bike user. The length of the individual sprints was adjusted according to the activities envisaged within the sprint.

Before each sprint, each ST had a meeting of what needed to be done within the upcoming sprint. After the sprint was over, a design review was made together with the customer and the requirements that needed to be solved within the next sprint were determined. The sequence of several sprints resulted in a stage where the result was checked with physical prototypes, some only with design (3D printed housings and connectors) and some with functional prototypes. The individual product subassemblies are interconnected but are not necessarily required for testing at all stages.

\subsection{Specificity of agile approach in the development of complex physical products}

The principles of agility and the methods that take these into account have been developed in the field of software development, which is in certain ways quite different from the development of physical products. Despite the differences, the principles of agility can also be taken into account in the development of physical products, but it is necessary to use individual agile methods, such as, for example, Scrum, adapted to specific processes that are characteristic for the development of complex physical products. No matter what type of product is being developed, the result of each sprint and stage should be an improved product. In software development, testing is possible in each sprint, while 
in the development of mechanical systems after the end of each sprint, only a VP is available, which allows limited testing options (numerical simulations, FMEA, etc.). Making a physical prototype (partial or complete) is, on the other hand, many times crucial but it requires longer execution times. The proposed agile methodology must be applied to different projects and enterprises with care. Specific circumstances and boundary conditions have to be considered.

According to the principles of agility, working prototypes are more important than extensive documentation. This principle is again somewhat easier to follow when developing software. In the development of physical products, at least for now, technical documentation is necessary both for prototype and serial production and assembly. With the transition to MBD the volume of documentation will undoubtedly decrease. When developing complex products, a lot of new knowledge is usually gained, especially when team members develop a particular product for the first time, which involves a constant learning process. Modern cloud-based tools can provide the necessary platform to quickly store and access all the produced project information in an organized fashion.

\section{CONCLUSION}

The study was carried out on a concrete industrial project, where, taking into account the combination of APD and simultaneous development, all challenges were promptly dealt with, which led to a high quality final product and a satisfied customer. Regular communication with the buyer and presentation of results in short time iterations/sprints proved to be the key to introducing changes as early as possible. A physical prototype is indispensable for testing and validating the functionality of complex physical products. The difference that occurs when compared to software development is that after the development of a prototype in a virtual environment, physical products still require a certain amount of time and cost to build physical prototypes. The ST must identify which parts of the product can be further developed during the production of the physical prototype, otherwise time is lost while waiting for the prototype. Regular communication with the customer enables the introduction of changes at the earliest possible stages of development. A special feature of the development of physical products is that it is necessary to properly prepare and plan the entire production long before the final prototype is available. Despite the fact that the study was conducted on a successfully completed project, the critical review identified some shortcomings and problems during development. Based on these and taking into account the successfully implemented steps, guidelines were developed, according to which it is possible to develop complex mechatronic products taking into account the principles of APD.

\section{REFERENCES}

Beck, Kent M., Mike Beedle, Arie van Bennekum, A. Cockburn, W. Cunningham, M. Fowler, J. Grenning, et al. 2001. "Manifesto for Agile Software Development." 2001.

Bernard, R. 1999. "Early Evaluation of Product Properties within the Integrated Product Development", Dissertation, Lehrstuhl für Konstruktion im Maschinenbau, Technical University of Munich, Munich.

Böhmer, A.I. 2018. When Digital Meets Physical - Agile Innovation of Mechatronic Systems, dissertation, Lehrstuhl für Produktentwicklung und Leichtbau, Technical university Munich.

Chen, Jiyao, Richard R. Reilly, and Gary S. Lynn. 2012. "New Product Development Speed: Too Much of a Good Thing?" Journal of Product Innovation Management 29 (2): 288-303. https://doi.org/10.1111/j.15405885.2011.00896.x.

Duhovnik, Jožef, and Jože Tavčar. 2015. “Concurrent Engineering in Machinery.” In Concurrent Engineering in the 21st Century: Foundations, Developments and Challenges, edited by Josip Stjepandić, Nel Wognum, and Wim J.C. Verhagen, 639-70. Cham: Springer International Publishing. https://doi.org/10.1007/978-3319-13776-6_22.

Gövert, K. 2020. Implementing Agile Development in Mechatronic Product Development Processes, dissertation, Lehrstuhl für Produktentwicklung und Leichtbau, Technical university Munich.

Islam, Gibrail, and Tim Storer. 2020. "A Case Study of Agile Software Development for Safety-Critical Systems Projects.” Reliability Engineering \& System Safety 200 (August): 106954. https://doi.org/10.1016/j.ress.2020.106954.

Leite, Marco, A.J. Baptista, and A.M.R. Ribeiro. 2016. “A Road Map for Implementing Lean and Agile Techniques in SMEs Product Development Teams." International Journal of Product Development 21 (1): 20. https://doi.org/10.1504/IJPD.2016.076922.

Leite, Marco, and Vanessa Braz. 2016. “Agile Manufacturing Practices for New Product Development: Industrial Case Studies.” Journal of Manufacturing Technology Management 27 (4): 560-76. https://doi.org/10.1108/JMTM-09-2015-0073. 
Ovesen, N. 2012. "The Challenges of Becoming Agile: Implementing and Conducting Scrum in Integrated Product Development." Denmark: Department of Architecture \& Design, Aalborg University.

Potdar, Pavan Kumar, and Srikanta Routroy. 2018. "Analysis of Agile Manufacturing Enablers: A Case Study." Materials Today: Proceedings, 7th International Conference of Materials Processing and Characterization, March 17-19, 2017, 5 (2, Part 1): 4008-15. https://doi.org/10.1016/j.matpr.2017.11.660.

Potdar, Pavan Kumar, Srikanta Routroy, and Astajyoti Behera. 2017. “Agile Manufacturing: A Systematic Review of Literature and Implications for Future Research.” Benchmarking: An International Journal 24 (7): 2022-48. https://doi.org/10.1108/BIJ-06-2016-0100.

Raj, S. Aravind, A. Sudheer, S. Vinodh, and G. Anand. 2013. "A Mathematical Model to Evaluate the Role of Agility Enablers and Criteria in a Manufacturing Environment.” International Journal of Production Research 51 (19): 5971-84. https://doi.org/10.1080/00207543.2013.825381.

Reichwein, Jannik, Sven Vogel, Stefan Schork, and Eckhard Kirchner. 2020. “On the Applicability of Agile Development Methods to Design for Additive Manufacturing." Procedia CIRP, Enhancing design through the 4th Industrial Revolution Thinking, 91 (January): 653-58. https://doi.org/10.1016/j.procir.2020.03.112.

Riesener, Michael, Eric Rebentisch, Christian Dölle, Sebastian Schloesser, Maximillian Kuhn, Jan Radermacher, and Günther Schuh. 2019. "A Model for Dependency-Oriented Prototyping in the Agile Development of Complex Technical Systems.” Procedia CIRP, 29th CIRP Design Conference 2019, 08-10 May 2019, Póvoa de Varzim, Portgal, 84 (January): 1023-28. https://doi.org/10.1016/j.procir.2019.04.196.

Schwaber, Ken, and Jeff Sutherland. 2017. "The Scrum Guide: The Definitive Guide to Scrum: The Rules of the Game." https://www.scrumguides.org/docs/scrumguide/v2017/2017-Scrum-Guide-US.pdf.

Smith, Preston G. 2007. Flexible Product Development: Building Agility for Changing Markets. Wiley \& Sons.

Sommer, Anita Friis, Christian Hedegaard, Iskra Dukovska-Popovska, and Kenn Steger-Jensen. 2015. "Improved Product Development Performance through Agile/Stage-Gate Hybrids: The Next-Generation Stage-Gate Process?" Research-Technology Management 58 (1): 34-45. https://doi.org/10.5437/08956308X5801236.

Stare, Aljaž. 2014. "Agile Project Management in Product Development Projects.” Procedia - Social and Behavioral Sciences, Selected papers from the 27th IPMA (International Project Management Association), World Congress, Dubrovnik, Croatia, 2013, 119 (March): 295-304. https://doi.org/10.1016/j.sbspro.2014.03.034.

Stjepandić, Josip, Nel Wognum, and Wim J. C. Verhagen, eds. 2015. Concurrent Engineering in the 21st Century: Foundations, Developments and Challenges. Springer International Publishing. https://doi.org/10.1007/978-3-319-13776-6.

Tam, Carlos, Eduardo Jóia da Costa Moura, Tiago Oliveira, and João Varajão. 2020. “The Factors Influencing the Success of On-Going Agile Software Development Projects.” International Journal of Project Management 38 (3): 165-76. https://doi.org/10.1016/j.ijproman.2020.02.001.

Tavčar, Jože, Ivan Demšar, and Jožef Duhovnik. 2018. "Engineering Change Management Maturity Assessment Model with Lean Criteria for Automotive Supply Chain.” Journal of Engineering Design 29 (4-5): $235-57$. https://doi.org/10.1080/09544828.2018.1463513.

Vinodh, S., S. R. Devadasan, S. Maheshkumar, M. Aravindakshan, M. Arumugam, and K. Balakrishnan. 2010. "Agile Product Development through CAD and Rapid Prototyping Technologies: An Examination in a Traditional Pump-Manufacturing Company.” The International Journal of Advanced Manufacturing Technology 46 (5): 663-79. https://doi.org/10.1007/s00170-009-2142-4.

Younas, Muhammad, Dayang N. A. Jawawi, Imran Ghani, Terrence Fries, and Rafaqut Kazmi. 2018. "Agile Development in the Cloud Computing Environment: A Systematic Review.” Information and Software Technology 103 (November): 142-58. https://doi.org/10.1016/j.infsof.2018.06.014. 